\title{
No improvement in depressive symptoms by vitamin D supplementation: results from a randomised controlled trial
}

\author{
Rolf Jorde ${ }^{1,2 *}$ and Julia Kubiak ${ }^{1}$ \\ ${ }^{1}$ Tromso Endocrine Research Group, Department of Clinical Medicine, UiT The Arctic University of Norway, Tromso, Norway \\ ${ }^{2}$ Division of Internal Medicine, University Hospital of North Norway, Tromsa, Norway
}

(Received 21 September 2018 - Accepted 10 October 2018)

Journal of Nutritional Science (2018), vol. 7, e30, page 1 of 7

doi:10.1017/jns.2018.19

Abstract

In observational studies, vitamin D deficiency is associated with depressive symptoms. However, randomised controlled trials (RCT) with vitamin D supplementation have not been conclusive. In the present study 206 subjects were randomised to vitamin D (100 $000 \mathrm{IU}$ (2500 $\mu \mathrm{g})$ as a bolus dose followed by $20000 \mathrm{IU}(500 \mu \mathrm{g})$ per week) and 202 to placebo. The Beck Depression Inventory-II (BDI-II) was filled in at baseline and after 4 months at the end of the study. At baseline the mean age was 51.4 and 52.5 years and mean serum 25-hydroxyvitamin $\mathrm{D}(25(\mathrm{OH}) \mathrm{D}) 32.5$ and $35.1 \mathrm{nmol} / 1 \mathrm{in}$ the vitamin D and placebo groups, respectively. Among the 408 subjects, 193 had a BDI-II score $>4$, and forty-five had a score $>13$. Twenty-three subjects were using antidepressant or mood-stabilising drugs. At the end of the study, there were no significant differences in $\Delta$ BDI-II score (score at the end of the study minus score at baseline), regardless of analysing all subjects, subjects with or without psycopharmaca, or if performing subgroup analyses based on baseline and final serum 25(OH)D levels combined with categories of baseline BDI-II scores $>4$ or $>13$. In conclusion, we have not been able to demonstrate any significant effect of vitamin D supplementation on depressive symptoms. However, few of our subjects were clinically depressed. Future RCT should include subjects with more severe vitamin D deficiency as well as more depressed subjects than in our study. In such a setting vitamin D may probably be more relevant as an augmenter of standard antidepressant medication/treatment.

Key words: Beck Depression Inventory: Depression: Randomised controlled trials: Vitamin D

Vitamin D is essential for Ca metabolism and bone health ${ }^{(1)}$, but may also be important for brain development and function ${ }^{(2-4)}$. This is reasonable, since vitamin D metabolites may cross the blood-brain barrier ${ }^{(5)}$, and the vitamin D receptor as well as the enzymes necessary for the activation of vitamin $\mathrm{D}$ to its active form 1,25-dihydroxyvitamin $\mathrm{D}$ are present in the central nervous system ${ }^{(6,7)}$. Furthermore, vitamin D deficiency has been associated with impaired cognitive function and psychiatric symptoms like depression in several observational studies ${ }^{(8,9)}$. However, it has been difficult to demonstrate a causal relationship between vitamin D deficiency and depression.
Since sun-induced production of vitamin $\mathrm{D}$ in the skin is the main vitamin $\mathrm{D}$ source ${ }^{(1)}$, the low levels of serum 25-hydroxyvitamin D $(25(\mathrm{OH}) \mathrm{D})$, which is used as a marker of vitamin $\mathrm{D}$ status ${ }^{(1)}$, could be the result and not the cause of depression. The only way to settle this question is through properly performed randomised controlled trials (RCT), but the results of those performed so far are not conclusive ${ }^{(10-15)}$. One reason for the apparent lack of effect of vitamin D supplementation could be that the subjects included were not vitamin $\mathrm{D}$ insufficient (serum $25(\mathrm{OH}) \mathrm{D}<50 \mathrm{nmol} / \mathrm{l})^{(16)}$ and, accordingly, no benefit from additional vitamin $\mathrm{D}$ was to be expected. Thus, in the nine RCT that met the inclusion criteria

Abbreviations: 25(OH)D, 25-hydroxyvitamin D; BDI-II, Beck Depression Inventory-II; PTH, parathyroid hormone; RCT, randomised controlled trial.

* Corresponding author: Rolf Jorde, fax +47 77669730, email rolf.jorde@unn.no

(C) The Author(s) 2018. This is an Open Access article, distributed under the terms of the Creative Commons Attribution licence (http://creativecommons.org/licenses/by/4.0/), which permits unrestricted re-use, distribution, and reproduction in any medium, provided the original work is properly cited. 
for meta-analysis by Gowda et al. ${ }^{(13)}$ on vitamin D supplementation to reduce depression in adults published in 2015, only two RCT had mean baseline serum 25(OH)D below 50 nmol/l. Furthermore, the mean serum $25(\mathrm{OH}) \mathrm{D}$ levels in these two studies were as high as 45 and $47 \mathrm{nmol} / \mathrm{l}^{(17,18)}$, and the effect of vitamin D deficiency on depressive symptoms was therefore not truly tested.

In Tromsø, Northern Norway, large population-based health surveys are performed at 6- to 8 -year intervals ${ }^{(19)}$. The seventh was conducted in 2015/2016 and included serum $25(\mathrm{OH}) \mathrm{D}$ measurements in more than 20000 subjects. We were therefore able to invite a large number of subjects with low serum $25(\mathrm{OH}) \mathrm{D}$ levels in an RCT on vitamin D and depressive symptoms. Our main hypothesis was that supplementation with vitamin $\mathrm{D}$ would improve depressive symptoms as evaluated with the Beck Depression Inventory-II (BDI-II). Furthermore, we wanted to perform subgroup analyses in the subjects with low baseline vitamin 25(OH)D levels and with high BDI-II scores since these were the subjects where an effect of vitamin D supplementation most likely would be seen.

\section{Methods}

\section{Subjects and study design}

The main endpoint in the vitamin $\mathrm{D}$ intervention study was cardiovascular risk factors, and the design of the study and the main endpoint results have been reported in detail ${ }^{(20)}$. In short, the subjects were recruited from the Tromsø Study, which is a population-based health survey in the municipality of Tromsø in northern Norway at $69^{\circ}$ north ${ }^{(19)}$. The seventh survey was performed in 2015/2016 and all citizens aged 40 years and above (n 32591) were invited, 21083 attended, serum $25(\mathrm{OH}) \mathrm{D}$ successfully measured in 20922 , and 1489 subjects with serum values $<42 \mathrm{nmol} / 1$ and with age $<80$ years invited by mail to participate in the present study. The cut-off of $42 \mathrm{nmol} / \mathrm{l}$ was chosen as this was estimated to result in a sufficient number of subjects with vitamin D insufficiency where an effect of vitamin $D$ supplementation could be expected $^{(8)}$. A total of 698 subjects responded and 639 were screened by telephone for the following exclusion criteria: known granulomatous disease, diabetes, renal stones in the last 5 years, serious diseases making the subject unfit for participation, use of vitamin D supplements $>800 \mathrm{IU}(20 \mu \mathrm{g})$ vitamin $\mathrm{D}$ per $\mathrm{d}$, use of solarium on a regular basis, and planned holiday(s) in tropical areas during the study period. Women of childbearing potential without use of acceptable contraception were excluded.

A total of 455 subjects passed this initial telephone screening and attended the first visit at the Clinical Research Unit at the University Hospital of North Norway where the informed consent form was signed, clinical examinations performed, medical history taken and blood samples drawn. These examinations did not reveal any contraindication for participation in 422 subjects who then attended the next visit within $2-5 \mathrm{~d}$. At this second (non-fasting) visit, the BDI-II was filled in and the study drugs (Dekristol cholecalciferol capsules (20 $000 \mathrm{IU}$;
$500 \mu \mathrm{g})$; Mibe $\mathrm{GmbH}$ ) or identical-looking placebo capsules containing arachis oil (Ayanda GmbH \& Co. KG) were dispensed. Five capsules were given as a loading dose followed by one capsule each week.

The randomisation was stratified according to sex, vitamin D status in the Tromsø Study (above/below $25 \mathrm{nmol} / \mathrm{l}$ ), smoking status (current smoker yes/no) and BMI above/ below $27 \mathrm{~kg} / \mathrm{m}^{2}$. All nurses, doctors, other study personnel and study participants were blinded throughout the study. The subjects were asked not to take any vitamin D supplements (including cod liver oil) during the intervention period.

After 4 months the third and fourth visits were performed, identical to the first and the second. Unused medication was returned and counted. Compliance was calculated as the ratio between capsules used (capsules supplied minus capsules returned) and number of weeks between the second and fourth visits. In all, 411 subjects attended the last visit. Among these, 408 subjects (206 given vitamin D and 202 placebo) had complete BDI-II scores both at baseline and at the end of the study and were included in the analyses.

\section{Measurements}

The subjects were asked regarding anti-depressant or mood-stabilising drugs (psychopharmaca), and classified as users/non-users of psychopharmaca. Height and weight were measured wearing light clothing without shoes and BMI calculated as weight $(\mathrm{kg})$ divided by height squared $\left(\mathrm{m}^{2}\right)$. Serum $\mathrm{Ca}(\mathrm{mmol} / \mathrm{l})$ was analysed by using the Hitachi 917 (Roche Diagnostics), with reagents from BoehringerMannheim. Serum parathyroid hormone (PTH) level (pmol/l) was measured using an Immulite 2000 Intact PTH analyser (Siemens Healthcare Diagnostics). Serum 25(OH)D $(\mathrm{nmol} / \mathrm{l}$ ) was measured with an in-house liquid chromatography-tandem MS method that detects both $25(\mathrm{OH}) \mathrm{D}_{3}$ and $25(\mathrm{OH}) \mathrm{D}_{2}$ and the sum of these is presented as $25(\mathrm{OH}) \mathrm{D}$ in the results. The assay has a between-day $\mathrm{CV}$ of $<9 \%$, and a within-day $\mathrm{CV}$ of $<2 \%{ }^{(21)}$.

The BDI-II questionnaire consists of twenty-one items, each with four statements ${ }^{(22)}$. The subjects are asked to choose the statement that best describes their condition during the last 2 weeks. The statements are rated from 0 (normal or least depressed mood) to 3 (most depressed mood). The BDI-II score was obtained by adding all the values together. A score $0-13$ is considered as none or minimal depression, 14-19 as mild depression, 20-28 as moderate depression and $29-63$ as severe depression ${ }^{(23)}$. The BDI-II score varies considerably between populations, with mean scores of about 9 and medians of 6-7 in most non-clinical samples ${ }^{(24,25)}$.

\section{Statistical analyses}

Normal distribution was evaluated with skewness and kurtosis and visual inspection of histograms and found normal for all parameters except the BDI-II scores at baseline and at the end of the study. However, the $\Delta$ BDI-II scores (value at the end of the study minus value at baseline) were normally distributed. 
Correlations were evaluated at baseline with Spearman's rho. Comparisons between groups (men/women, smokers/nonsmokers, users/non-users of psychopharmaca, and the vitamin D/placebo groups) at baseline were performed with Student's $t$ test, $\chi^{2}$ test or the Mann-Whitney $U$ test.

Comparisons between baseline and end of study values within the vitamin $\mathrm{D}$ and placebo groups were performed with Student's $t$ test or the Mann-Whitney $U$ test. Comparisons between the vitamin $\mathrm{D}$ and placebo groups at the end of the study were performed with a general linear model with value at the end of the study as the dependent variable, sex and randomisation status as fixed factors, and age and baseline value as covariates ${ }^{(26)}$. For the BDI-II score the $\Delta$ values (which were normally distributed) were used as dependent variables in this analysis. The distribution of the BDI-II scores at the end of the study across categories of end of study serum 25(OH)D $(<25,25-49,50-74$, and $>74 \mathrm{nmol} / \mathrm{l}$ ) was evaluated with the Kruskal-Wallis test.

$P<0.05$ (two-tailed) was considered statically significant. Data are presented as means and standard deviations or as medians and ranges. All statistical analyses were performed using IBM SPSS version 22 software.

\section{Power calculation}

For the main endpoint of the study, cardiovascular risk factors (systolic blood pressure, serum LDL-cholesterol, insulin resistance (by homeostatic model assessment; HOMA)), a total number of 450 subjects was needed if wanting a power of 0.8 and $P<0 \cdot 05^{(20)}$. For depression, the BDI scores were not normally distributed, and a formal power calculation was therefore not performed. We have in a previous vitamin $\mathrm{D}$ intervention study in 441 subjects with mean serum $25(\mathrm{OH})$ $\mathrm{D}$ of $52.5 \mathrm{nmol} / 1$ found a slight but significant improvement after vitamin D supplementation as compared with placebo ${ }^{(27)}$. In the present study we aimed to include a similar number of subjects but with substantially lower serum $25(\mathrm{OH}) \mathrm{D}$ levels. Assuming that an effect of vitamin D supplementation would be more pronounced in vitamin D-insufficient subjects, 450 subjects were considered to give the study reasonable power. However, we have now performed a post hoc calculation using the normally distributed $\Delta$ BDI-II values. Assuming a standard deviation for the $\Delta$ BDI-II score of $4 \cdot 3$, a power of 0.8 and $P<0 \cdot 05,408$ included subjects should be sufficient to detect a difference in $\Delta$ BDI-II of 1.2 between the two groups.

\section{Ethics}

The study was approved by the Regional Committee for Medical Research Ethics (REK NORD 2013/1464) and by the Norwegian Medicines Agency (2013-003514-40). The study is registered at ClinicalTrials.gov (NCT02750293). All subjects gave their written informed consent.

\section{Results}

The baseline characteristics of the 408 subjects included in the analyses are shown in Table 1 . There were no significant correlations between BDI-II score and age, BMI, serum $\mathrm{Ca}$, PTH or $25(\mathrm{OH}) \mathrm{D}$ at baseline, nor were there significant differences between men and women, smokers and non-smokers regarding BDI-II (data not shown). Subjects using psychopharmaca (n 23) had significantly lower mean serum 25(OH)D levels than subjects not using psychopharmaca (n 385) (28.9 (SD 9.6) nmol/1 v. 34.1 (sD 12.6) nmol/l; $P<0.05$ ), and they also had significantly higher median BDI-II scores (11 (range 1-23) v. 4 (range 0-25); $P<0.001$ ) (Table 1, Figs 1 and 2).

At baseline there were no significant differences between the vitamin $\mathrm{D}$ and placebo groups, except for the mean serum 25 $(\mathrm{OH}) \mathrm{D}$ level which was slightly lower in the vitamin $\mathrm{D}$ group than the placebo group $(32.5$ (sD 11.1) nmol/l v. 35.1 (SD 13.6) $\mathrm{nmol} / \mathrm{l} ; P<0.05$ ) (Table 2). Inclusion in relation to season was also similar in the two groups, with most of the

Table 1. Baseline characteristics of all subjects and in those without or with the use of psychopharmaca (Mean values and standard deviations, numbers of subjects, percentages; medians and ranges)

\begin{tabular}{|c|c|c|c|c|c|c|}
\hline & \multicolumn{2}{|c|}{ All subjects ( $n$ 408) } & \multicolumn{2}{|c|}{$\begin{array}{c}\text { Subjects not using } \\
\text { psychopharmaca (n 385) }\end{array}$} & \multicolumn{2}{|c|}{$\begin{array}{c}\text { Subjects using } \\
\text { psychopharmaca (n 23) }\end{array}$} \\
\hline & Mean & SD & Mean & SD & Mean & SD \\
\hline Age (years) & $52 \cdot 0$ & $8 \cdot 8$ & $52 \cdot 0$ & $8 \cdot 6$ & $52 \cdot 0$ & $10 \cdot 0$ \\
\hline \multicolumn{7}{|l|}{$\operatorname{Sex}(n)$} \\
\hline Males & \multicolumn{2}{|c|}{217} & \multicolumn{2}{|c|}{205} & \multicolumn{2}{|c|}{12} \\
\hline Females & \multicolumn{2}{|c|}{191} & \multicolumn{2}{|c|}{180} & \multicolumn{2}{|c|}{11} \\
\hline Current smokers (\%) & \multicolumn{2}{|c|}{$22 \cdot 1$} & \multicolumn{2}{|c|}{$21 \cdot 0$} & \multicolumn{2}{|c|}{$39 \cdot 1^{*}$} \\
\hline $\mathrm{BMI}$ at baseline $\left(\mathrm{kg} / \mathrm{m}^{2}\right)$ & $27 \cdot 8$ & $4 \cdot 8$ & $27 \cdot 8$ & $4 \cdot 8$ & $28 \cdot 0$ & $4 \cdot 8$ \\
\hline Serum Ca at baseline (mmol/l) & $2 \cdot 27$ & 0.07 & $2 \cdot 27$ & 0.07 & $2 \cdot 28$ & 0.07 \\
\hline Serum PTH at baseline $(\mathrm{pmol} / \mathrm{l})$ & $6 \cdot 7$ & $2 \cdot 0$ & $6 \cdot 7$ & $2 \cdot 0$ & $6 \cdot 8$ & $2 \cdot 2$ \\
\hline Serum $25(\mathrm{OH}) \mathrm{D}$ at baseline $(\mathrm{nmol} / \mathrm{l})$ & $33 \cdot 8$ & $12 \cdot 5$ & $34 \cdot 1$ & $12 \cdot 6$ & $28.9 \dagger$ & $9 \cdot 6$ \\
\hline BDI-II score at baseline§ & 4 & $0-25$ & 4 & $0-25$ & $11 \ddagger$ & $1-23$ \\
\hline
\end{tabular}

PTH, parathyroid hormone; 25(OH)D, 25-hydroxyvitamin D; BDI-II, Beck Depression Inventory-II.

${ }^{*}$ Proportion was significantly different from that of subjects not using psychopharmaca $\left(P<0.05 ; \chi^{2}\right.$ test).

† Mean value was significantly different from that of subjects not using psychopharmaca $(P<0.05$; Student's $t$ test).

$\ddagger$ Median value was significantly different from that of subjects not using psychopharmaca $(P<0.001$; Mann-Whitney $U$ test).

$\S$ Medians and ranges. 


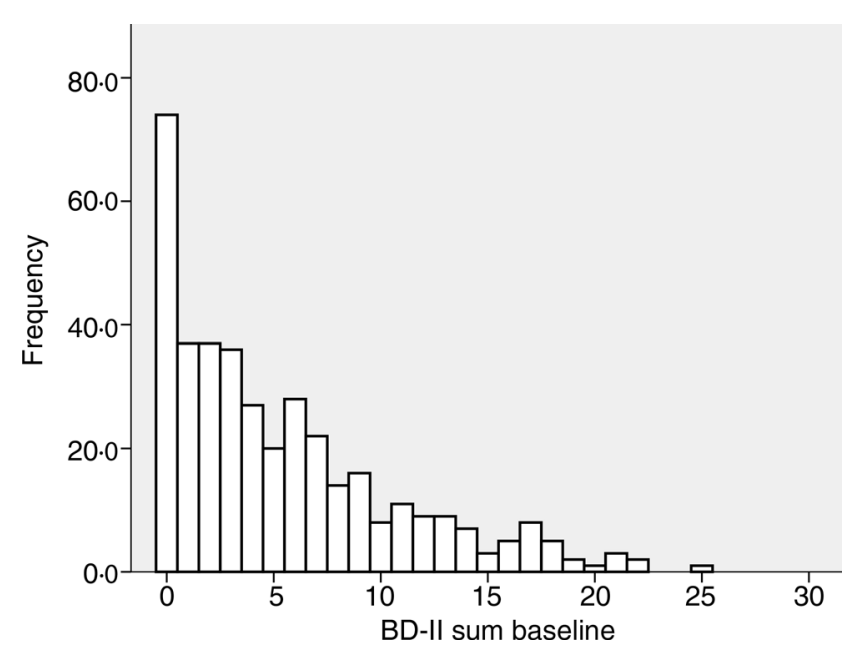

Fig. 1. Frequency of Beck Depression Inventory-II (BDI-II) scores at baseline in the 385 subjects not using anti-depressant or mood-stabilising drugs.

subjects included during the winter months (Supplementary Figs S1 and S2).

At the end of the study there was an increase in serum 25 $(\mathrm{OH}) \mathrm{D}$ of about $56 \mathrm{nmol} / \mathrm{l}$ in the vitamin $\mathrm{D}$ group and a decrease in the placebo group of about $4 \mathrm{nmol} / \mathrm{l}$; the serum Ca level was significantly higher and the serum PTH significantly lower in the vitamin D group than the placebo group (Table 2).

In both the vitamin D and placebo groups the final BDI-II scores were significantly lower than the baseline scores $(P<$ 0.05). However, the $\Delta$ BDI-II scores did not differ significantly between the vitamin D and placebo group, both when including all subjects and when analysing users and non-users of psychopharmaca separately (Table 2 and Fig. 3).

To test our hypothesis that an effect of vitamin D supplementation would most likely be seen in subjects with low baseline vitamin $25(\mathrm{OH}) \mathrm{D}$ levels and with high BDI-II scores, subgroup analyses were performed. Thus, subjects with baseline serum $25(\mathrm{OH}) \mathrm{D}<50 / 40 / 30 \mathrm{nmol} / 1 \mathrm{combined}$ with final serum $25(\mathrm{OH}) \mathrm{D}$ value $>70 \mathrm{nmol} / 1$ in the vitamin $\mathrm{D}$ group,

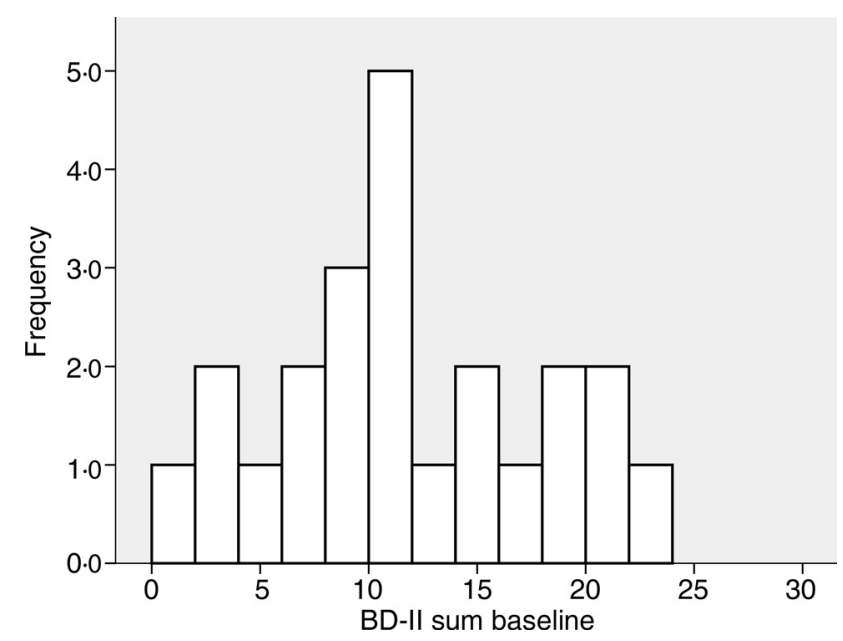

Fig. 2. Frequency of Beck Depression Inventory-II (BDI-II) scores at baseline in the twenty-three subjects using anti-depressant or mood-stabilising drugs. and baseline and final serum $25(\mathrm{OH}) \mathrm{D}<50 / 40 / 30 \mathrm{nmol} / 1$ in the placebo group were analysed separately. However, this did not disclose significant differences in $\Delta$ BDI-II regardless of if inclusion was additionally restricted to subjects with BDI-II scores $>4$ or $>13$ at baseline (Table 3).

Furthermore, when taking all the 408 subjects together, there were no correlations at the end of the study between $\Delta$ BDI-II score and $\Delta 25(\mathrm{OH}) \mathrm{D}$; nor were there any significant trend for BDI-II score across categories of final serum 25 $(\mathrm{OH}) \mathrm{D}$ values of $0-24 \mathrm{nmol} / 1$ ( $n$ 57), 25-49 nmol/1 ( $n$ 139), 50-74 nmol/1 ( $n$ 52), and $>74 \mathrm{nmol} / 1$ (n 160) (data not shown).

No serious study-related side effects were recorded. Two subjects developed hypercalcaemia (serum $\mathrm{Ca}=2.57$ $\mathrm{mmol} / \mathrm{l}$ ); one male whose serum $\mathrm{Ca}$ normalised upon retesting, and one female who was found to have developed primary hyperparathyroidism. The compliance rate in the study was very high; $14 \%$ of the subjects had a compliance rate between 84 and $100 \%$, and the rest a compliance rate of $100 \%$.

\section{Discussion}

In the present study we found both in the vitamin D and placebo groups a significant reduction in depressive symptoms as evaluated by the BDI-II score. However, when comparing the changes in the two groups, no significant effect of the vitamin $\mathrm{D}$ supplementation on the BDI-II score was found, even if restricting the analyses to subjects with low serum $25(\mathrm{OH}) \mathrm{D}$ levels and mild depression. The reduction in the BDI-II scores from baseline in both groups therefore probably reflects an effect of repeated testing ${ }^{(28)}$.

We have in two previous studies showed slight, but significant, effects of vitamin D supplementation on depressive symptoms. Thus, in a study on 441 overweight subjects with a mean baseline serum 25(OH)D level of $53 \mathrm{nmol} / \mathrm{l}$, we found a relationship between baseline serum $25(\mathrm{OH}) \mathrm{D}$ and BDI score, and a positive effect on BDI in those given vitamin $\mathrm{D}$ over a 1 -year period as compared with placebo ${ }^{(27)}$. In the other study, that included 243 subjects with a mean baseline serum 25(OH)D level of $47 \mathrm{nmol} / 1$, the effect was only seen in post hoc analyses on those with high BDI score at baseline, and in only one out of the four depression tests employed ${ }^{(18)}$. In view of our present finding, we do consider our previous reports of positive vitamin $\mathrm{D}$ effects on depression as due to chance.

Several meta-analyses and reviews on vitamin D and depression have been published, and there is a general agreement that in observational studies there is an association between vitamin $\mathrm{D}$ deficiency and depressive symptoms ${ }^{(10-15)}$. However, for intervention studies, there appears to be no clear-cut effect, and many of these studies have been of low quality. Thus, in a systematic review by Spedding ${ }^{(12)}$ it was reported that out of fifteen RCT included, eight had obvious biological flaws and were not properly designed. This was confirmed in the latest meta-analysis on the topic that included nine RCT with 4923 participants ${ }^{(13)}$. In none of these nine trials was the mean baseline serum 25(OH)D level below 40 $\mathrm{nmol} / \mathrm{l}$, and in only one, where the mean baseline serum 25 
Table 2. Baseline and end of study values in all subjects and in those without or with the use of psychopharmaca (Mean values and standard deviations; numbers of subjects; medians and ranges)

\begin{tabular}{|c|c|c|c|c|c|c|c|c|c|c|c|c|}
\hline & \multicolumn{4}{|c|}{ All subjects } & \multicolumn{4}{|c|}{$\begin{array}{l}\text { Subjects not using } \\
\text { anti-depressants/ } \\
\text { psychopharmaca }\end{array}$} & \multicolumn{4}{|c|}{$\begin{array}{l}\text { Subjects using } \\
\text { anti-depressants/ } \\
\text { psychopharmaca }\end{array}$} \\
\hline & \multicolumn{2}{|c|}{$\begin{array}{c}\text { Vitamin D } \\
\text { group }(n 206)\end{array}$} & \multicolumn{2}{|c|}{$\begin{array}{c}\text { Placebo } \\
\text { group (n 202) }\end{array}$} & \multicolumn{2}{|c|}{$\begin{array}{c}\text { Vitamin D } \\
\text { group }(n 192)\end{array}$} & \multicolumn{2}{|c|}{$\begin{array}{c}\text { Placebo } \\
\text { group }(n 193)\end{array}$} & \multicolumn{2}{|c|}{$\begin{array}{c}\text { Vitamin D } \\
\text { group }(n 14)\end{array}$} & \multicolumn{2}{|c|}{$\begin{array}{l}\text { Placebo } \\
\text { group }(n 9)\end{array}$} \\
\hline & Mean & SD & Mean & SD & Mean & SD & Mean & SD & Mean & SD & Mean & SD \\
\hline Age (years) & 51.4 & 8.6 & 52.5 & 8.7 & $51 \cdot 3$ & 8.4 & $52 \cdot 6$ & $8 \cdot 8$ & 53.0 & $10 \cdot 9$ & $50 \cdot 3$ & 8.8 \\
\hline \multicolumn{13}{|l|}{$\operatorname{Sex}(n)$} \\
\hline Males & \multicolumn{2}{|c|}{109} & \multicolumn{2}{|c|}{108} & \multicolumn{2}{|c|}{102} & \multicolumn{2}{|c|}{103} & \multicolumn{2}{|c|}{7} & \multicolumn{2}{|c|}{5} \\
\hline Females & \multicolumn{2}{|c|}{97} & \multicolumn{2}{|c|}{94} & \multicolumn{2}{|c|}{90} & \multicolumn{2}{|c|}{90} & \multicolumn{2}{|c|}{7} & \multicolumn{2}{|c|}{4} \\
\hline $\mathrm{BMI}$ at baseline $\left(\mathrm{kg} / \mathrm{m}^{2}\right)$ & $27 \cdot 8$ & 5.0 & 27.9 & $4 \cdot 7$ & $27 \cdot 7$ & 5.0 & $27 \cdot 9$ & 4.7 & $29 \cdot 0$ & $5 \cdot 3$ & $26 \cdot 4$ & 3.5 \\
\hline $\mathrm{BMI}$ at the end of the study $\left(\mathrm{kg} / \mathrm{m}^{2}\right)$ & $28 \cdot 0$ & 5.0 & 28.0 & 4.8 & 27.9 & $5 \cdot 0$ & 28.0 & $4 \cdot 8$ & $29 \cdot 3$ & 5.5 & $26 \cdot 6$ & 3.4 \\
\hline Serum $\mathrm{Ca}$ at baseline $(\mathrm{mmol} / \mathrm{l})$ & $2 \cdot 27$ & 0.07 & 2.27 & 0.70 & $2 \cdot 27$ & 0.07 & 2.27 & 0.07 & $2 \cdot 28$ & 0.07 & 2.29 & 0.09 \\
\hline Serum $\mathrm{Ca}$ at the end of the study $(\mathrm{mmol} / \mathrm{l})$ & $2 \cdot 29^{* *}$ & 0.08 & $2 \cdot 27$ & 0.07 & $2 \cdot 29^{\star *}$ & 0.08 & $2 \cdot 27$ & 0.07 & $2 \cdot 27$ & 0.07 & $2 \cdot 25$ & 0.07 \\
\hline Serum PTH at baseline $(\mathrm{pmol} / \mathrm{l})$ & 6.7 & $2 \cdot 2$ & $6 \cdot 8$ & 1.9 & 6.6 & $2 \cdot 1$ & $6 \cdot 8$ & 1.9 & $7 \cdot 2$ & $2 \cdot 6$ & $6 \cdot 2$ & $1 \cdot 1$ \\
\hline Serum PTH at the end of the study (pmol/l) & $5 \cdot 9^{\star \star \star}$ & 2.0 & 7.3 & $2 \cdot 2$ & $5 \cdot 9^{\star \star \star *}$ & 1.9 & 7.3 & $2 \cdot 2$ & 6.5 & $2 \cdot 2$ & $7 \cdot 0$ & 1.4 \\
\hline Serum $25(\mathrm{OH}) \mathrm{D}$ at baseline $(\mathrm{nmol} / \mathrm{l})$ & 32.5 & $11 \cdot 1$ & $35 \cdot 1$ & $13 \cdot 6$ & 32.8 & $11 \cdot 2$ & 35.4 & 13.7 & $28 \cdot 3$ & 9.0 & 29.8 & 11.0 \\
\hline Serum $25(\mathrm{OH}) \mathrm{D}$ at the end of the study $(\mathrm{nmol} / \mathrm{l})$ & $88 \cdot 8^{\star \star \star}$ & 19.5 & 30.7 & 9.7 & $89 \cdot 3^{\star \star \star}$ & $18 \cdot 8$ & $30 \cdot 8$ & $9 \cdot 8$ & $82 \cdot 2^{\star \star \star}$ & $27 \cdot 3$ & 28.1 & 8.0 \\
\hline BDI-II score at baseline $\dagger$ & 4.0 & $0-25$ & 4.0 & $0-23$ & 4.0 & $0-25$ & 4.0 & $0-22$ & 10.5 & $1-21$ & 14.0 & $4-23$ \\
\hline BDI-II score at the end of the study $†$ & $2 \cdot 0$ & $0-27$ & $2 \cdot 0$ & $0-2$ & $2 \cdot 0$ & $0-27$ & $2 \cdot 0$ & $0-32$ & 5.5 & $0-15$ & $9 \cdot 0$ & $1-27$ \\
\hline Change in BDI-II score & -1.5 & 4.3 & -1.9 & 4.1 & -1.4 & 4.3 & -1.9 & 4.1 & $-2 \cdot 8$ & 3.3 & $-2 \cdot 6$ & 4.7 \\
\hline
\end{tabular}

PTH, parathyroid hormone; 25(OH)D, 25-hydroxyvitamin D; BDI-II, Beck Depression Inventory-II.

Mean value was significantly different from that of the corresponding placebo group: ${ }^{\star \star} P<0.01,{ }^{\star \star \star} P<0.001$ (linear regression with baseline value, age and sex as covariates) † Medians and ranges.

$(\mathrm{OH}) \mathrm{D}$ level was $58 \mathrm{nmol} / \mathrm{l}$ and the randomisation procedure unclear $^{(13)}$, were the participant recruited on the basis of clinical depression ${ }^{(29)}$. The conclusion of that meta-analysis was therefore no surprise: no significant reduction in depression after vitamin D supplementation. It was also recommended that future RCT should be performed among individuals who are both depressed and vitamin $\mathrm{D}$ deficient ${ }^{(13)}$.

In our study we aimed at recruiting the subjects with the lowest serum $25(\mathrm{OH}) \mathrm{D}$ levels measured in a population-based health survey (the Troms $\varnothing$ Study) that included more than 20 000 subjects. All the 408 subjects included had a serum 25 $(\mathrm{OH}) \mathrm{D}$ value $<42 \mathrm{nmol} / 1$ in the Tromsø Study, but since the intervention started up to 4 months later for some of the subjects, not all were vitamin D insufficient (serum 25 $(\mathrm{OH}) \mathrm{D}<50 \mathrm{nmol} / \mathrm{l})$ at baseline. However, in the vitamin D group 163 subjects had baseline serum 25(OH)D $<50$ $\mathrm{nmol} / \mathrm{l}$ and with final serum $25(\mathrm{OH}) \mathrm{D}>70 \mathrm{nmol} / \mathrm{l}$ (as an indication of adequate effect of the supplementation), and

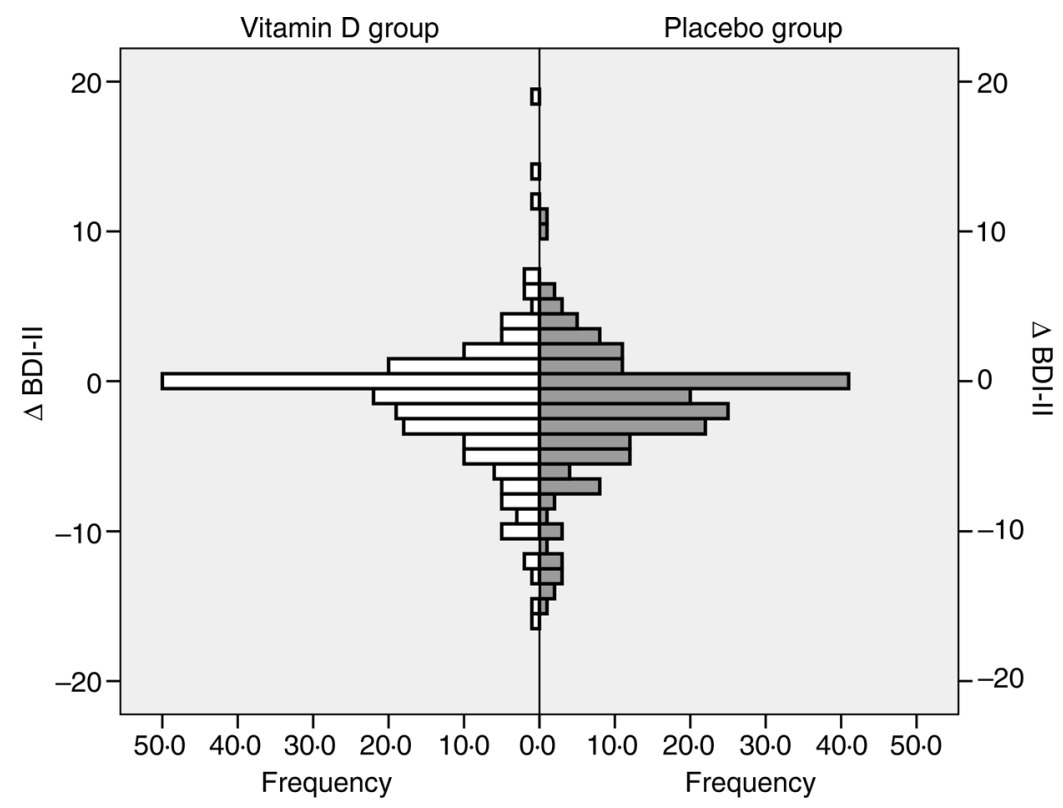

Fig. 3. Change in Beck Depression Inventory-II ( $\Delta$ BDI-II) score (score at the end of the study minus score at baseline) in the vitamin $\mathrm{D}$ and placebo groups, all subjects included. 
Table 3. Change in Beck Depression Inventory-II ( $\triangle$ BDI-II) scores (score at the end of the study minus score at baseline) in relation to baseline and final serum 25-hydroxyvitamin D $(25(\mathrm{OH}) \mathrm{D})$ levels and baseline BDI-II scores*

(Mean values and standard deviations)

\begin{tabular}{|c|c|c|c|c|c|c|}
\hline & \multicolumn{3}{|c|}{ Vitamin D group } & \multicolumn{3}{|c|}{ Placebo group } \\
\hline & \multirow[b]{2}{*}{$n$} & \multicolumn{2}{|c|}{$\Delta \mathrm{BDI}-\mathrm{II}$ score } & \multirow[b]{2}{*}{$n$} & \multicolumn{2}{|c|}{$\Delta \mathrm{BDI}-\mathrm{Il}$ score } \\
\hline & & Mean & SD & & Mean & SD \\
\hline \multicolumn{7}{|c|}{ All subjects regardless of baseline and final $25(\mathrm{OH}) \mathrm{D}$ levels } \\
\hline Regardless of baseline BDI-II score & 208 & -1.5 & 4.3 & 202 & -1.9 & 4.1 \\
\hline Baseline BDI-II score >4 & 100 & $-3 \cdot 2$ & $5 \cdot 2$ & 93 & -3.8 & 5.0 \\
\hline Baseline BDI-II score $>10$ & 18 & $-7 \cdot 1$ & 5.5 & 27 & -4.9 & 7.4 \\
\hline \multicolumn{7}{|c|}{ Subjects with baseline $25(\mathrm{OH}) \mathrm{D}<50 \mathrm{nmol} / \mathrm{l}$, and final $25(\mathrm{OH}) \mathrm{D}>70 \mathrm{nmol} / \mathrm{l}$ in the vitamin $\mathrm{D}$ group and final $25(\mathrm{OH}) \mathrm{D}<50 \mathrm{nmol} / \mathrm{l}$ in the placebo group } \\
\hline Regardless of baseline BDI-II score & 163 & -1.4 & 4.4 & 165 & $-2 \cdot 0$ & 4.3 \\
\hline Baseline BDI-II score $>4$ & 76 & $-3 \cdot 1$ & 5.5 & 76 & -4.0 & 5.2 \\
\hline Baseline BDI-II score $>10$ & 15 & $-6 \cdot 6$ & 5.5 & 24 & $-5 \cdot 1$ & 7.4 \\
\hline \multicolumn{7}{|c|}{ Subjects with baseline $25(\mathrm{OH}) \mathrm{D}<40 \mathrm{nmol} / \mathrm{l}$, and final $25(\mathrm{OH}) \mathrm{D}>70 \mathrm{nmol} / \mathrm{l}$ in the vitamin $\mathrm{D}$ group and final $25(\mathrm{OH}) \mathrm{D}<40 \mathrm{nmol} / \mathrm{l}$ in the placebo group } \\
\hline Regardless of baseline BDI-II score & 136 & -1.9 & $4 \cdot 2$ & 126 & -2.4 & 4.2 \\
\hline Baseline BDI-II score $>4$ & 66 & $-3 \cdot 8$ & $5 \cdot 0$ & 57 & $-4 \cdot 7$ & 4.9 \\
\hline Baseline BDI-II score $>10$ & 14 & $-7 \cdot 1$ & 5.4 & 17 & -6.4 & 6.4 \\
\hline \multicolumn{7}{|c|}{ Subjects with baseline $25(\mathrm{OH}) \mathrm{D}<30 \mathrm{nmol} / \mathrm{l}$, and final $25(\mathrm{OH}) \mathrm{D}>70 \mathrm{nmol} / \mathrm{l}$ in the vitamin $\mathrm{D}$ group and final $25(\mathrm{OH}) \mathrm{D}<30 \mathrm{nmol} / \mathrm{l}$ in the placebo group } \\
\hline Regardless of baseline BDI-II score & 74 & -1.3 & 3.6 & 52 & $-2 \cdot 0$ & 4.5 \\
\hline Baseline BDI-II score $>4$ & 36 & $-2 \cdot 6$ & 4.6 & 23 & -4.4 & $5 \cdot 1$ \\
\hline Baseline BDI-II score $>10$ & 7 & -5.4 & 2.5 & 7 & $-6 \cdot 7$ & 5.4 \\
\hline
\end{tabular}

* Vitamin $\mathrm{D}$ analysed $v$. corresponding placebo group with linear regression with baseline value, age and sex as covariates. $P>0.05$ for all comparisons.

168 subjects in the placebo group had baseline and final serum $25(\mathrm{OH}) \mathrm{D}<50 \mathrm{nmol} / \mathrm{l}$. Among these, thirty-nine subjects (of whom eight were using anti-depressant medication) had a baseline BDI-II score $>13$ and could thus be classified as being mildly or more depressed. Thus, the ideal study group, depressed, vitamin D-insufficient subjects, was therefore rather small. However, no trend in favour of an effect of vitamin D supplementation was seen, nor when restricting the inclusion to subjects with even lower baseline serum $25(\mathrm{OH})$ D levels.

We have previously published the cross-sectional relationship between serum 25(OH)D and depressive symptoms (evaluated by the Hopkins Symptoms Check List 10) from the sixth survey in the Tromsø Study with more than 12000 subjects included in the analyses ${ }^{(8)}$. Although there was a highly significant relationship, the difference in serum 25 $(\mathrm{OH}) \mathrm{D}$ between those who were in the highest depression score quartile $v$. those in the lowest was only about $6 \%$. Accordingly, even if there is a causal relationship between serum $25(\mathrm{OH}) \mathrm{D}$ and depression, it is unlikely that vitamin $\mathrm{D}$ is of major importance. It also follows that a large number of subjects need to be included to demonstrate an effect, especially if those included only have minor depressive symptoms.

In subjects with severe depressive symptoms, it might also be unethical to try treatment with vitamin $\mathrm{D}$ alone, even if the subjects are vitamin D insufficient. In clinical trials recruiting such patients, vitamin $\mathrm{D}$ would appear to be more suited as an add-on treatment ${ }^{(15)}$.

As discussed above, our study has weaknesses, in particular since most of our subjects were not clinically depressed. We did not perform a formal power calculation before the start of the study. However, a post hoc calculation (that as such should be viewed with caution) indicated that we should have had power to detect a difference in $\Delta$ BDI-II score of 1.2 between the two groups. Thus, we should have been able to detect any clinically meaningful effect of the supplementation. As we did eleven subgroup analyses the statistical power of these analyses was considerably reduced, and the subgroup analyses should be considered as exploratory only. We used weekly vitamin D supplementation, and daily doses may be more efficient if the serum level of unhydroxylated vitamin D (cholecalciferol) is important ${ }^{(30)}$. It has been reported that the relationship between vitamin $\mathrm{D}$ and depressive symptoms is only seen during the summer months ${ }^{(31)}$. This may indicate that vitamin D-independent effects of sunlight may be drivers for the association between $25(\mathrm{OH})$ $\mathrm{D}$ and depression, or perhaps that the relationship is dependent upon serum level of vitamin D (cholecalciferol), that presumably is very low during the winter, and not $25(\mathrm{OH}) \mathrm{D}^{(30)}$. Furthermore, many of our subjects were included during the winter months and therefore came to the final visit during early spring. If season is important and depression less pronounced in the spring, that may also have masked effects of the vitamin D supplementation. We also used only one depression score instrument, which may not have picked up more subtle changes. Also, finally, our study only lasted 4 months, and we cannot exclude that to see an effect of vitamin D a longer intervention period is needed. On the other hand, our study does have strength and importance as it demonstrates the futility of searching for vitamin D effects on depression in cohorts where the depression score is low, even in vitamin $\mathrm{D}$ insufficiency.

\section{Acknowledgements}

The superb assistance from the staff at the Clinical Research Unit (and in particular Bjørg Skog Høgset and Britt-Ann Winther Eilertsen) and the Department of Medical Biochemistry at the University Hospital of North Norway is gratefully acknowledged. 
The study was supported by grants from the North Norway Regional Health Authorities (grant number SFP1277-16) and UiT, The Arctic University of Norway.

The contributions of the authors were as follows: formulating the research questions, R. J.; designing the study, R. J., carrying out the study, R. J. and J. K.; analysing the data and writing the article, R. J. and J. K.

There were no conflicts of interest.

\section{Supplementary material}

The supplementary material for this article can be found at https://doi.org/10.1017/jns.2018.19

\section{References}

1. DeLuca HF (2004) Overview of general physiologic features and functions of vitamin D. Am J Clin Nutr 80, 6 Suppl., 1689S-1696S.

2. Eyles D, Brown J, Mackay-Sim A, et al. (2003) Vitamin $D_{3}$ and brain development. Neuroscience 118, 641-653.

3. Garcion E, Wion-Barbot N, Montero-Menei CN, et al. (2002) New clues about vitamin D functions in the nervous system. Trends Endocrinol Metab 13, 100-105.

4. McCann JC \& Ames BN (2008) Is there convincing biological or behavioral evidence linking vitamin $\mathrm{D}$ deficiency to brain dysfunction? FASEB J 22, 982-1001.

5. Pardridge WM, Sakiyama R \& Coty WA (1985) Restricted transport of vitamin $\mathrm{D}$ and A derivatives through the rat blood-brain barrier. J Neurocbem 44, 1138-1141.

6. Stumpf WE, Sar M, Clark SA, et al. (1982) Brain target sites for 1,25-dihydroxyvitamin $\mathrm{D}_{3}$. Science 215, 1403-1405.

7. Zehnder D, Bland R, Williams MC, et al. (2001) Extrarenal expression of 25-hydroxyvitamin $\mathrm{D}_{3}-1$ alpha-hydroxylase. J Clin Endocrinol Metab 86, 888-894.

8. Kjærgaard M, Joakimsen R \& Jorde R (2011) Low serum 25-hydroxyvitamin $\mathrm{D}$ levels are associated with depression in an adult Norwegian population. Psychiatry Res 190, 221-225.

9. Hoogendijk WJ, Lips P, Dik MG, et al. (2008) Depression is associated with decreased 25-hydroxyvitamin $\mathrm{D}$ and increased parathyroid hormone levels in older adults. Arch Gen Psychiatry 65, 508-512.

10. Shaffer JA, Edmondson D, Wasson LT, et al. (2014) Vitamin D supplementation for depressive symptoms: a systematic review and meta-analysis of randomized controlled trials. Psychosom Med 76, 190-196.

11. Li G, Mbuagbaw L, Samaan Z, et al. (2014) Efficacy of vitamin D supplementation in depression in adults: a systematic review. J Clin Endocrinol Metab 99, 757-767.

12. Spedding S (2014) Vitamin D and depression: a systematic review and meta-analysis comparing studies with and without biological flaws. Nutrients 6, 1501-1518.

13. Gowda U, Mutowo MP, Smith BJ, et al. (2015) Vitamin D supplementation to reduce depression in adults: meta-analysis of randomized controlled trials. Nutrition 31, 421-429.
14. Okereke OI \& Singh A (2016) The role of vitamin D in the prevention of late-life depression. J Affect Disord 198, 1-14.

15. Parker GB, Brotchie H \& Graham RK (2017) Vitamin D and depression. J Affect Disord 208, 56-61.

16. Ross AC, Manson JE, Abrams SA, et al. (2011) The 2011 report on dietary reference intakes for calcium and vitamin $\mathrm{D}$ from the Institute of Medicine: what clinicians need to know. J Clin Endocrinol Metab 96, 53-58.

17. Arvold DS, Odean MJ, Dornfeld MP, et al. (2009) Correlation of symptoms with vitamin $\mathrm{D}$ deficiency and symptom response to cholecalciferol treatment: a randomized controlled trial. Endocr Pract 15, 203-212.

18. Kjærgaard M, Waterloo K, Wang CE, et al. (2012) Effect of vitamin D supplement on depression scores in people with low levels of serum 25-hydroxyvitamin D: nested case-control study and randomised clinical trial. Br J Psychiatry 201, 360-368.

19. Jacobsen BK, Eggen AE, Mathiesen EB, et al. (2012) Cohort profile: the Tromso study. Int J Epidemiol 41, 961-967.

20. Kubiak JM, Thorsby PM, Kamycheva E, et al. (2018) Vitamin D supplementation does not improve CVD risk factors in vitamin D-insufficient subjects. Endocr Connect 7, 840-849.

21. Sollid ST, Hutchinson MY, Fuskevåg OM, et al. (2014) No effect of high-dose vitamin D supplementation on glycemic status or cardiovascular risk factors in subjects with prediabetes. Diabetes Care 37, 2123-2131.

22. Steer RA, Clark DA, Beck AT, et al. (1999) Common and specific dimensions of self-reported anxiety and depression: the BDI-II versus the BDI-IA. Behav Res Ther 37, 183-190.

23. Furukawa TA (2010) Assessment of mood: guides for clinicians. J Psychosom Res 68, 581-589.

24. Whisman MA \& Richardson ED (2015) Normative data on the Beck Depression Inventory - second edition (BDI-II) in college students. J Clin Psychol 71, 898-907.

25. Wang YP \& Gorenstein C (2013) Psychometric properties of the Beck Depression Inventory-II: a comprehensive review. Rev Bras Psiquiatr 35, 416-431.

26. Vickers AJ \& Altman DG (2001) Statistics notes: analysing controlled trials with baseline and follow up measurements. Br Med J 323, 1123-1124.

27. Jorde R, Sneve M, Figenschau Y, et al. (2008) Effects of vitamin D supplementation on symptoms of depression in overweight and obese subjects: randomized double blind trial. J Intern Med 264, 599-609.

28. Choquette KA \& Hesselbrock MN (1987) Effects of retesting with the Beck and Zung depression scales in alcoholics. Alcohol Alcohol 22, 277-283.

29. Khoraminya N, Tehrani-Doost M, Jazayeri S et al. (2013) Therapeutic effects of vitamin $\mathrm{D}$ as adjunctive therapy to fluoxetine in patients with major depressive disorder. Aust N Z J Psychiatry 47, 271-275.

30. Jorde R \& Grimnes G (2018) Serum cholecalciferol may be a better marker of vitamin D status than 25-hydroxyvitamin D. Med Hypotheses 111, 61-65.

31. Rabenberg M, Harisch C, Rieckmann N, et al. (2016) Association between vitamin $\mathrm{D}$ and depressive symptoms varies by season: results from the German Health Interview and Examination Survey for Adults (DEGS1). J Affect Disord 204, 92-98. 